\title{
Response of Sorghum Accessions from Four African Countries against Colletotrichum sublineolum, Causal Agent of Sorghum Anthracnose
}

\author{
Louis K. Prom ${ }^{1}$, John Erpelding ${ }^{2}$, Ramasamy Perumal ${ }^{3}$, Thomas Isakeit ${ }^{4}$, Hugo Cuevas ${ }^{5}$ \\ ${ }^{1}$ USDA-ARS, Southern Plains Agricultural Research Center, College Station, USA; ${ }^{2}$ USDA-ARS, Mid South Area, Crop Genetics \\ Research Unit, Stoneville, USA; ${ }^{3}$ Western Kansas Agricultural Research Center, Kansas State University, Hays, USA; ${ }^{4}$ Department \\ of Plant Pathology and Microbiology, Texas A\&M University, College Station, USA; ${ }^{5}$ USDA-ARS, Tropical Agriculture Research \\ Station, Mayaguez, Puerto Rico. \\ Email: louis.prom@ars.usda.gov
}

Received October $13^{\text {th }}, 2011$; revised November $9^{\text {th }}, 2011$; accepted November $29^{\text {th }}, 2011$

\begin{abstract}
Seventy-two sorghum accessions were randomly selected from the Ethiopia, Mali, Sudan, and Uganda germplasm collections maintained by the US National Plant Germplasm System to evaluate variation in anthracnose resistance. The accessions were planted in a randomized complete block design in College Station, Texas during the 2007 and 2008 growing seasons. Twenty-six accessions exhibited a resistant response across growing seasons with 8 accessions showing a susceptible response. Twenty-nine accessions showed variation in disease response within and between experiments. Seven accessions were rated as resistant in 2007 but showed a susceptible reaction in 2008. The frequency of resistant germplasm varied based on country of origin with $80 \%$ of the accessions from Mali, $48 \%$ of the accessions from Uganda, 24\% of the accessions from Sudan, and 7\% of the accessions from Ethiopia exhibiting a resistance response. When the same accessions were evaluated in Isabela, Puerto Rico, $100 \%$ of the accessions from Mali, $43 \%$ of the accessions from Uganda, and $28 \%$ of the accessions from Sudan exhibited a resistant response. All the accessions from Ethiopia were susceptible to anthracnose when evaluated in Isabela, Puerto Rico. In both locations, 22 accessions exhibited a resistant response. Four accessions rated as resistant in Texas were found to be susceptible in Puerto Rico; whereas, five accessions rated as resistant in Puerto Rico showed a susceptible response in Texas. These results indicated that the Mali, Sudan, and Uganda sorghum collections may be an important source of anthracnose resistance. However, the identification of anthracnose resistant germplasm from many diverse regions could result in the identification of new sources of genetic variation for resistance. Also, greater genetic variation for resistance could be present in regions with a high frequency of resistant germplasm.
\end{abstract}

Keywords: Sorghum; Anthracnose; Colletotrichum sublineolum; Disease Response; Germplasm

\section{Introduction}

Sorghum anthracnose, caused by Colletotrichum sublineolum P. Henn., Kabát \& Bubák, is one of the most destructive foliar diseases and, presently, it is found in most sorghum growing regions [1-5]. The pathogen infects all above-ground parts of the plants with infection of leaves more commonly observed as compared to infection of the stalks and panicles. Foliar infection can occur at any stage of plant development, but symptoms are generally observed 40 days after seedling emergence [5]. The symptoms on the leaves will depend on the type of cultivar planted and environmental conditions. Symptoms can range from small, circular or elliptical spots to elongated necrotic lesions with abundant acervuli forma- tion [5]. Under severe conditions, the pathogen will cause premature defoliation and thereby delaying the development of the plant [5]. Panicle infection phase of the disease affects both the quality and quantity of the grain [5]. Grain yield losses of up to 50\% may occur under severe foliar infection on susceptible cultivars; whereas panicle infection can result in losses ranging from $30 \%-50 \%[3,5,6]$. Yield loss is primarily due reduction in grain number and size [5]. The occurrence of different pathotypes and levels of pathogenicity within the pathogen population require the identification of additional sources of resistance [1-3,7]. Thus, the objectives of this study were to evaluate subsets of sorghum accessions collected from four African countries to identify new sources of anthracnose resistance and to determine if 
resistance was associated with country of origin.

\section{Materials and Methods}

Seventy-two sorghum accessions were randomly selected from the germplasm collections of four African countries, which included 14 accessions from Ethiopia, 10 accessions from Mali, 25 accessions from Sudan, and 23 accessions from Uganda. Seed samples for the evaluation were obtained from the USDA-ARS, Plant Genetic Resources Conservation Unit, Griffin, Georgia. BTx623 was included as a susceptible control and SC748-5 was the resistant control genotype. The anthracnose evaluation was conducted during the 2007 and 2008 growing seasons at the Texas AgriLIFE Experiment Station, College Station, Texas and also at the USDA-ARS, Tropical Agriculture Research Station in Isabela, Puerto Rico. Accessions were planted in a randomized complete block design, with each accession replicated three times. Seed was planted in $6 \mathrm{~m}$ rows at $0.31 \mathrm{~m}$ spacing between rows. Field preparation included fall plowing and incorporation of the compound fertilizer at $175 \mathrm{~kg} \mathrm{~N} / \mathrm{ha}$, and 116.5 $\mathrm{kg} / \mathrm{ha}$ for both $\mathrm{P}_{2} \mathrm{O}_{5}$ and $\mathrm{K}_{2} \mathrm{O}$. An additional $175 \mathrm{~kg} \mathrm{~N} / \mathrm{ha}$ was applied as top dressing five weeks after planting. To control weeds and seedling insects, a pre-emergent insecticide "Counter 20 CR" (BASF Group, Southfield, MI) and herbicide "Atrazine" (Syngenta Crop Protection Inc. Greenboro, NC) were applied before planting. In Isabela, Puerto Rico, each accession also replicated three times was planted in a single row of $1.8 \mathrm{~m}$ in length with $0.9 \mathrm{~m}$ spacing. A border row of an anthracnose susceptible genotype (PI 561472) was planted around the experimental fields. Fertilizer was applied at a rate of $560 \mathrm{~kg} / \mathrm{ha} \mathrm{(15-}$ 5-10 NPK) during planting. Lorsban 15G (Chlorpyrifos) granular insecticide (Dow AgroSciences, Indianapolis, IN) was applied at a rate of $8 \mathrm{~kg} / \mathrm{ha}$ during planting to prevent seed loss from fire ants. Weeds were controlled with mechanical tillage and hand hoeing.

The inoculation technique and disease assessment method were previously described by Erpelding and Prom [8] and Prom et al. [9]. Briefly, sorghum plants were inoculated 30 days after planting by placing $10 \mathrm{C}$. sublineolum-colonized grains into the leaf whorls using a mixture of 7 isolates of the pathogen. Disease assessments were conducted 30 days post-inoculation and thereafter, on a weekly basis for four consecutive weeks. Ratings were based on a scale of 1 to 5 , where $1=$ no symptoms or chlorotic flecks on leaves; 2 hypersensitive reaction (reddening or red spots) on inoculated leaves but no acervuli formation and no symptoms observed on other leaves; $3=$ lesions on inoculated and bottom leaves with acervuli in the center; $4=$ necrotic lesions with acervuli observed on inoculated and bottom leaves with infection spreading to middle leaves; and $5=$ most leaves dead due to infection with infection on the flag leaf containing abundant acervuli. The symptom types were then categorized into two reaction classes, resistant $=$ rated as 1 or 2; and susceptible $=$ rated as 3, 4, or 5 . In cases where there was variation in disease response within accession, each replication was assigned a single score value and recorded. Except for a few accessions, the final disease response type for each accession was based on the majority of the disease response of the replications for the accession.

\section{Statistical Analysis}

Using the numerical values (rating scale of 1 to 5), data were subjected to the analysis of variance using the command PROC GLIMMIX (SAS version 9.2, SAS Institute, Cary, NC) to determine the main effect of sorghum accessions.

\section{Results and Discussion}

The hyper-variable nature of $C$. sublineolum requires the identification of new sources of resistance in order to breed resistant varieties. In this study, the anthracnose response was significantly affected by accession $(P<$ $0.01)$. Across the two growing seasons in Texas, 26 accessions conferred a resistant response and 10 accessions showed a susceptible response (Table 1). Variation in disease response was observed within and between experiments for 29 accessions. This may be due to the fact that some of the sorghum landraces or accessions in the collection are heterogeneous. Five accessions exhibited susceptibility to anthracnose in all but one replication; whereas six accessions, PI276797, PI297204, PI305034, PI454164, PI568660, and PI569066, were rated as resistant in 2007 but showed susceptible response in 2008. Variation in susceptibility between replications was more frequent in 2007 with 21 accessions rated as susceptible in at least one replication. When the same accessions were evaluated in multiple years in Isabela, Puerto Rico, 27 accessions exhibited a resistant response, 44 accessions were rated as susceptible, and 5 accessions exhibited a variable response (Table 1).

In this study, 22 accessions PI608974, PI608986, PI608990, PI608992, PI609009, PI609015, PI609947, PI609991, PI277674, PI568373, PI568533, PI568637, PI570743, PI570873, PI154748, PI154788, PI154966, PI297093, PI297215, PI330983, PI584033, and PI584283 exhibited a resistant response in both Texas and Puerto Rico. Four accessions rated as resistant in Texas were found to be susceptible in Puerto Rico; whereas, five accessions rated as resistant in Puerto Rico showed a susceptible response in Texas. This indicates that there 
Table 1. Disease reaction of 72 accessions from Ethiopia, Mali, Sudan, and Uganda and two controls to inoculation with Colletotrichum sublineolum under field conditions ${ }^{1}$.

\begin{tabular}{|c|c|c|c|c|c|c|c|c|}
\hline & & & & \multicolumn{3}{|c|}{ College Station, TX } & \multicolumn{2}{|l|}{ Isabela, PR } \\
\hline & & & & 2007 & 2008 & & & \\
\hline Accession & Origin & Race & Plant Color & Rating & Rating & $\mathrm{CS}^{2}$ & Rating & $\mathrm{PR}^{3}$ \\
\hline BTX 623 & US & Caudatum & red & 5 & 5 & S & 5 & S \\
\hline SC 748-5 & Sudan & Caudatum & purple & 2 & 2 & $\mathrm{R}$ & 2 & $\mathrm{R}$ \\
\hline PI196054 & Ethiopia & Durra & ${ }_{-}^{4}$ & 3 & 4 & S & 5 & S \\
\hline PI196891 & Ethiopia & Bicolor & _ & 3 & 4 & S & 5 & S \\
\hline PI251637 & Ethiopia & _ & _ & 2 & 2 & $\mathrm{R}$ & $2 \backslash 4^{*}$ & S \\
\hline PI276797 & Ethiopia & Guinea-Caudatum & purple-red & 2 & 3 & S & 5 & S \\
\hline PI302134 & Ethiopia & _- & _- & $1 / 2 / 4^{*}$ & 3 & S & 5 & S \\
\hline PI305022 & Ethiopia & _- & _ & $1 / 3 / 4^{*}$ & 4 & S & 5 & S \\
\hline PI305034 & Ethiopia & _ & _ & 2 & 3 & S & 5 & S \\
\hline PI305035 & Ethiopia & _ & _ & 1 & $2 / 3 / 4^{*}$ & S & 5 & S \\
\hline PI305044 & Ethiopia & _ & _ & 3 & 3 & S & 5 & S \\
\hline PI305056 & Ethiopia & _ & _ & $1 / 3 / 3^{*}$ & $2 / 3 / 3^{*}$ & S & $2 \backslash 4^{*}$ & S \\
\hline PI329771 & Ethiopia & _ & _ & $2 / 3^{*}$ & $2 / 3^{*}$ & S & $2 \backslash 4^{*}$ & S \\
\hline РI330794 & Ethiopia & _- & _- & 3 & 3 & S & 4 & S \\
\hline PI454096 & Ethiopia & Durra & red-purple & $1 / 1 / 2^{*}$ & $2 / 3 / 4^{*}$ & S & - & \\
\hline PI454164 & Ethiopia & Bicolor & red-purple & 1 & 3 & S & 5 & S \\
\hline PI585687 & Mali & Durra & purple-red & $2 / 2 / 3^{*}$ & $2 / 3^{*}$ & S & 2 & $\mathrm{R}$ \\
\hline PI608974 & Mali & Durra & purple-red & 2 & 2 & $\mathrm{R}$ & 2 & $\mathrm{R}$ \\
\hline PI608986 & Mali & Durra & purple-red & 2 & 2 & $\mathrm{R}$ & 2 & $\mathrm{R}$ \\
\hline PI608990 & Mali & Guinea & purple-red & 2 & 2 & $\mathrm{R}$ & 2 & $\mathrm{R}$ \\
\hline PI608992 & Mali & - & - & 1 & 2 & $\mathrm{R}$ & 2 & $\mathrm{R}$ \\
\hline PI609009 & Mali & Durra & red-purple & 1 & 2 & $\mathrm{R}$ & 2 & $\mathrm{R}$ \\
\hline PI609015 & Mali & Caudatum & purple-red & 2 & 2 & $\mathrm{R}$ & 2 & $\mathrm{R}$ \\
\hline PI609044 & Mali & Guinea & purple-red & $1 / 1 / 3^{*}$ & $2 / 3 / 3^{*}$ & S & 2 & $\mathrm{R}$ \\
\hline PI609947 & Mali & Guinea & red-purple & 2 & 2 & $\mathrm{R}$ & 2 & $\mathrm{R}$ \\
\hline PI609991 & Mali & Guinea & purple-red & 2 & 2 & $\mathrm{R}$ & 2 & $\mathrm{R}$ \\
\hline PI152634 & Sudan & Caudatum-Bicolor & purple & $4 / 1 / 3^{*}$ & 4 & S & 5 & S \\
\hline PI152687 & Sudan & Caudatum & purple & $3 / 2 / 3^{*}$ & $2 / 3^{*}$ & S & 4 & S \\
\hline PI217674 & Sudan & Caudatum & purple & 2 & 2 & $\mathrm{R}$ & 2 & $\mathrm{R}$ \\
\hline PI217891 & Sudan & _ & purple & 4 & $2 / 3^{*}$ & S & 5 & S \\
\hline PI563145 & Sudan & Guinea-Caudatum & purple & 3 & 5 & S & 5 & S \\
\hline PI563321 & Sudan & Caudatum & red & 3 & 4 & S & 5 & S \\
\hline PI563328 & Sudan & Caudatum & purple & $1 / 3 / 3^{*}$ & $2 / 3 / 3^{*}$ & S & 5 & S \\
\hline PI568284 & Sudan & Caudatum & red & 2 & $2 / 4 / 4^{*}$ & S & 5 & S \\
\hline PI568288 & Sudan & Caudatum & purple & 3 & 3 & S & 5 & S \\
\hline PI568373 & Sudan & Bicolor & purple & 2 & 2 & $\mathrm{R}$ & 2 & $\mathrm{R}$ \\
\hline PI568388 & Sudan & Guinea-Caudatum & purple & 1 & 3 & S & 5 & S \\
\hline PI568403 & Sudan & Caudatum & purple & $1 / 1 / 3^{*}$ & $2 / 2 / 3^{*}$ & S & 5 & S \\
\hline PI568406 & Sudan & Caudatum & purple & $2 / 3 / 3^{*}$ & $2 / 2 / 3^{*}$ & S & 4 & S \\
\hline PI568477 & Sudan & Caudatum & red & $1 / 2 / 3^{*}$ & 4 & S & 5 & S \\
\hline PI568485 & Sudan & Caudatum & red-purple & $1 / 3 / 4^{*}$ & 4 & S & 5 & S \\
\hline PI568533 & Sudan & Caudatum & red-purple & 2 & 2 & $\mathrm{R}$ & 2 & $\mathrm{R}$ \\
\hline PI568637 & Sudan & Caudatum & red & 2 & 2 & $\mathrm{R}$ & 2 & $\mathrm{R}$ \\
\hline PI568660 & Sudan & Caudatum & $\operatorname{mix}$ & 1 & 3 & $\mathrm{~S}$ & 5 & $\mathrm{~S}$ \\
\hline
\end{tabular}


Continued

\begin{tabular}{|c|c|c|c|c|c|c|c|c|}
\hline PI569049 & Sudan & Caudatum & purple-red & 1 & $2 / 3 / 3^{*}$ & S & 4 & S \\
\hline PI569066 & Sudan & Guinea-Kafir & red & 1 & 3 & S & 4 & S \\
\hline PI569076 & Sudan & Kafir-Caudatum & purple-red (GRIN) & $1 / 3 / 4^{*}$ & 4 & S & 5 & S \\
\hline PI570211 & Sudan & Caudatum & red & 2 & $2 / 2 / 3^{*}$ & S & 2 & $\mathrm{R}$ \\
\hline PI570743 & Sudan & Caudatum & $\tan$ & 2 & 2 & $\mathrm{R}$ & 2 & $\mathrm{R}$ \\
\hline PI570873 & Sudan & Caudatum & purple & 2 & 2 & $\mathrm{R}$ & 2 & $\mathrm{R}$ \\
\hline PI571386 & Sudan & Durra & purple-red & $1 / 2 / 3^{*}$ & $2 / 2 / 3^{*}$ & S & 5 & S \\
\hline PI154748 & Uganda & Guinea-Caudatum & purple-red & 2 & 2 & $\mathrm{R}$ & 2 & $\mathrm{R}$ \\
\hline PI154758 & Uganda & Guinea-Caudatum & purple & $2 / 2 / 3^{*}$ & $2 / 2 / 3^{*}$ & S & 2 & $\mathrm{R}$ \\
\hline PI154788 & Uganda & Caudatum & purple & 2 & 2 & $\mathrm{R}$ & 2 & $\mathrm{R}$ \\
\hline PI154804 & Uganda & Caudatum & purple & $2 / 3^{*}$ & $2 / 3^{*}$ & S & 4 & S \\
\hline PI154901 & Uganda & Caudatum & purple & 3 & 4 & S & 5 & S \\
\hline PI154966 & Uganda & Caudatum & purple & 2 & 2 & $\mathrm{R}$ & 2 & $\mathrm{R}$ \\
\hline PI154973 & Uganda & Caudatum & purple & 2 & 2 & $\mathrm{R}$ & $2 \backslash 4^{*}$ & $\mathrm{~S}$ \\
\hline PI297093 & Uganda & Durra-Caudatum & purple & 2 & 2 & $\mathrm{R}$ & 2 & $\mathrm{R}$ \\
\hline PI297128 & Uganda & Caudatum & purple & 3 & 3 & S & 5 & S \\
\hline PI297139 & Uganda & Caudatum & purple-red & 2 & 2 & $\mathrm{R}$ & $2 \backslash 5$ weak $^{*}$ & S \\
\hline PI297141 & Uganda & Caudatum & purple & 2 & $2 / 3 / 3^{*}$ & S & 5 & S \\
\hline PI297144 & Uganda & Caudatum & purple & 2 & $2 / 2 / 3^{*}$ & S & 5 & S \\
\hline PI297192 & Uganda & Durra & purple & $2 / 3 / 4^{*}$ & 3 & S & 5 & S \\
\hline PI297196 & Uganda & Durra-Caudatum & purple-red & $1 / 2 / 3^{*}$ & 3 & S & 5 & $\mathrm{~S}$ \\
\hline PI297204 & Uganda & _- & _- & 2 & 3 & S & 5 & S \\
\hline PI297212 & Uganda & - & - & 2 & 2 & $\mathrm{R}$ & 5 & $\mathrm{~S}$ \\
\hline PI297215 & Uganda & - & - & 2 & 2 & $\mathrm{R}$ & 2 & $\mathrm{R}$ \\
\hline PI297218 & Uganda & _ & - & 4 & 5 & S & 5 & $\mathrm{~S}$ \\
\hline PI330983 & Uganda & - & - & 2 & 2 & $\mathrm{R}$ & 2 & $\mathrm{R}$ \\
\hline PI584033 & Uganda & Caudatum & purple-red & 2 & 2 & $\mathrm{R}$ & 2 & $\mathrm{R}$ \\
\hline PI584214 & Uganda & Caudatum & red-purple & $2 / 2 / 3^{*}$ & $2 / 3 / 3^{*}$ & S & 5 & S \\
\hline PI584283 & Uganda & Caudatum & purple-red & 2 & 2 & $\mathrm{R}$ & 2 & $\mathrm{R}$ \\
\hline PI584284 & Uganda & Caudatum & red-purple & $2 / 3^{*}$ & $2 / 3^{*}$ & $\mathrm{~S}$ & 2 & $\mathrm{R}$ \\
\hline
\end{tabular}

${ }^{1}$ Sorghum accessions were planted at the Texas A\&M University Research Farm, Brazos Bottom near College Station, Texas and in Isabela, Puerto Rico. Ratings were based on a scale of 1 to 5 (Erpelding and Prom, 2004), where 1 = no symptoms or chlorotic flecks on leaves; 2 = hypersensitive reaction (reddening or red spots) on inoculated leaves but no acervuli formation; 3 = lesions on inoculated leaves and bottom leaves with acervuli in the center; 4 = necrotic lesions with acervuli on the bottom and middle leaves; and 5 = most leaves dead due to infection with infection on the flags leaf containing abundant acervuli. A rating of 1 or 2 is considered a resistant (R) response, whereas a rating of 3, 4, or 5 is considered a susceptible (S) response. Rows with a single value indicate no variation for disease response within an experiment. An accession with more than one disease response value indicates variation within experiment (data presented for the replications). ${ }^{2} \mathrm{CS}$ - response categories: resistant (R) or susceptible (S) for the accessions that were evaluated in College Station, Texas. ${ }^{3} \mathrm{PR}-$ response categories: resistant (R) or susceptible (S) for the accessions that were evaluated in Isabela, Puerto Rico. ${ }^{4}$ : data not available. ${ }^{*}$ Variation within accessions and between experiments.

are different pathotypes of $C$. sublineolum between the two locations. Forty accessions were found to be susceptible in both locations.

Environmental conditions during evaluation of sorghum germplasm have profound influence on anthracnose infection response [5,10]. Erpelding and Prom [11] also noted variation in anthracnose response between experiments conducted during the dry and rainy growing seasons in Puerto Rico. During the 2007 evaluation in Texas, the mean temperature was $28.7^{\circ} \mathrm{C}$, total precipitation $266 \mathrm{~mm}$, and 38 precipitation days in the period from June to August; in the same period in 2008, mean temperature was $29.7^{\circ} \mathrm{C}$, total precipitation $187 \mathrm{~mm}$, and 24 precipitation days. Although, the 2007 evaluation received more rainfall, there were less susceptible accessions when compared with the 2008 evaluation. This indicates that other factors also could influence anthracnose development.

The frequency of resistant germplasm from various regions of Africa could be used to identify germplasm collection for further evaluation. For this study, $80 \%$ of the accessions from Mali, $48 \%$ of the accessions from 
Uganda, $24 \%$ of the accessions from Sudan, and $7 \%$ of the accessions from Ethiopia exhibited a resistance response to anthracnose in Texas; whereas, in Puerto Rico, $100 \%$ of the accessions from Mali, $43 \%$ of the accessions from Uganda, and $28 \%$ of the accessions from Sudan exhibited a resistant response, and all the accessions from Ethiopia exhibited a susceptible response (Table 1). However, Erpelding and Prom [12] evaluated a different subset of sorghum germplasm from Ethiopia for anthracnose disease response during the dry and wet seasons in Isabela, Puerto Rico, and noted that 20 accessions exhibited a resistance response, 13 accessions were susceptible, and 9 accessions showed variation in disease response within and between the growing seasons. These results indicated that the Mali, Sudan, and Uganda sorghum collections may be an important source of anthracnose resistance. The US National Plant Germplasm System maintains $\sim 2400$ accessions from Mali and $\sim 1000$ accessions from Uganda, thus further evaluations of these collections could identify a significant number of resistant accessions. Even though the lowest frequency of resistant accessions was observed for the Ethiopian collection, germplasm from Ethiopia has been widely used in many breeding programs and germplasm from this region may provide new sources of genetic variation for anthracnose resistance since anthracnose pathotypes are highly variable between regions.

Disclaimer: Mention of trade names or commercial products in this publication is solely for the purpose of providing specific information and does not imply recommendations or endorsement by the US Department of Agriculture.

\section{REFERENCES}

[1] M. E. K. Ali and H. L. Warren, "Physiological Races of Colletotrichum graminicola on Sorghum,” Plant Disease, Vol. 71, No. 5, 1987, pp. 402-404. doi:10.1094/PD-71-0402

[2] K. F. Cardwell, P. R. Hepperly and R. A. Frederiksen, "Pathotypes of Colletotrichum graminicola and Seed Transmission of Sorghum Anthracnose," Plant Disease, Vol. 73, No. 3, 1989, pp. 255-257. doi:10.1094/PD-73-0255
[3] S. Pande, L. K. Mughogho, R. Bandyopadhyay and R. I. Karunakar, "Variation in Pathogenicity and Cultural Characteristics of Sorghum Isolates of Colletotrichum graminicola in India,” Plant Disease, Vol. 75, No. 8, 1991, pp. 778-783. doi:10.1094/PD-75-0778

[4] C. Sherriff, M. J. Whelan, G. M. Arnold and J. A. Bailey, "rDNA Sequence Analysis Confirms the Distinction between Colletotrichum graminicola and C. sublineolum," Mycological Research, Vol. 99, No. 4, 1995, pp. 475-478. doi:10.1016/S0953-7562(09)80649-7

[5] R. P. Thakur and K. Mathur, “Anthracnose,” Compendium of Sorghum Diseases, The American Phytopathological Society, St. Paul, 2000, pp. 10-12.

[6] H. K. Ngugi, A. M. Julian, S. B. King and B. J. Peacocke, "Epidemiology of Sorghum Anthracnose (Colletotrichum sublineolum) and Leaf Blight (Exserohilum turcicum) in Kenya,” Plant Pathology, Vol. 49, No. 1, 2000, pp. 129140. doi:10.1046/j.1365-3059.2000.00424.x

[7] C. R. Casela, A. S. Ferreira and R. E. Schaffert, "Physiological Races of Colletotrichum graminicola in Brazil," Sorghum and Millets Diseases, International Crops Research Institute for the Semi-Arid Tropics, Patancheru, 1992, pp. 209-212.

[8] J. E. Erpelding and L. K. Prom, "Evaluation of Malian Sorghum Germplasm for Resistance against Anthracnose,” Plant Pathology Journal, Vol. 3, No. 2, 2004, pp. 65-71. doi:10.3923/ppj.2004.65.71

[9] L. K. Prom, R. Perumal, J. E. Erpelding, T. Isakeit, N. Montes-Garcia and C. Magill, “A Pictorial Technique for Mass Screening of Sorghum Germplasm for Anthracnose (Colletotrichum sublineolum) Resistance,” The Open Agriculture Journal, Vol. 3, 2009, pp. 20-25.

[10] A. Chala, T. Alemu, L. K. Prom and A. M. Tronsmo, "Effect of Host Genotypes and Weather Variables on the Severity and Temporal Dynamics of Sorghum Anthracnose in Ethiopia," Plant Pathology Journal, Vol. 9, No. 1, 2010, pp. 39-46. doi:10.3923/ppj.2010.39.46

[11] J. E. Erpelding and L. K. Prom, "Variation for Anthracnose Resistance within the Sorghum Germplasm Collection from Mozambique, Africa," Plant Pathology Journal, Vol. 5, No. 1, 2006, pp. 28-34. doi:10.3923/ppj.2006.28.34

[12] J. E. Erpelding and L. K. Prom, "Response to Anthracnose Infection for a Subset of Ethiopian Sorghum Germplasm," Journal of Agriculture of the University of Puerto Rico, Vol. 93, No. 3-4, 2009, pp. 195-206. 